\title{
Mineralogical characterization of radioactive particles from Fukushima soil using $\mu$-XRD with synchrotron radiation
}

\author{
Satoko Motai ${ }^{*}$, Hiroki Mukai ${ }^{*}$, Tetsu Watanuki ${ }^{* *}$, Kenji OhwadA ${ }^{* *}$, Tatsuo FukudA ${ }^{* *}$, Akihiko MachidA ${ }^{* *}$, \\ Chisaki Kuramata*, Ryosuke KIKUCHI ${ }^{*}$, Tsuyoshi YaItA ${ }^{* *}$ and Toshihiro KogurE* \\ ${ }^{*}$ Department of Earth and Planetary Sciences, Graduate School of Science, The University of Tokyo, Tokyo 113-0033, Japan \\ ${ }^{* *}$ Quantum Beam Science Center, Japan Atomic Energy Agency, Sayo, Hyogo 679-5148, Japan
}

\begin{abstract}
Radioactive particles of around $50 \mu \mathrm{m}$ size were collected from highly contaminated soil in the Fukushima Prefecture, Japan, and characterized using micro X-ray diffraction with synchrotron radiation (SR- $\mu$-XRD). Two-dimensional diffraction patterns from individual particles rotated during $\mathrm{X}$-ray irradiation were recorded on a flat imaging plate and a one-dimensional diffraction profile, as a function of $2 \theta$, was derived from the pattern. Weathered biotite (WB) particles with plate-like morphology showed a broad peak corresponding to a basal reflection with $d=10-14 \AA$, indicating various degrees of vermiculitization. Another peak of $\sim 7 \AA$ was also detected in these WB particles, suggesting the parallel growth of kaolinite in the biotite particles. These characteristics were also found in the WB collected from an Abukuma granitic body, which is widespread in the eastern part of Fukushima. SR- $\mu-\mathrm{XRD}$ of radioactive soil particles consisting of fine minerals or of those rich in organic matter indicated that these particles contain very fine 2:1 type clay minerals alongside detrital rockforming minerals such as quartz and feldspar.
\end{abstract}

Keywords: Clay minerals, Fukushima nuclear accident, SR- $\mu-\mathrm{XRD}$, Radioactive particles, Weathered biotite

\section{INTRODUCTION}

The accident at the Fukushima Daiichi nuclear power plant in March 2011 released various radionuclides into the natural environment. Among them, radioactive cesium is particularly problematic because of the large quantity released, its relatively long half-life ( $30.2 \mathrm{yr}$ for Cs137), and its emission of gamma-rays with high energy. The adsorption and desorption of cesium are strongly dependent on the host materials and the surrounding environment (Kim and Kirkpatrick, 1997; Dumat and Staunton, 1999; Takahashi et al., 1999; Giannakopoulou et al., 2007; Bellenger and Saunton, 2008). Hence, to understand the state and fate of radioactive cesium in the environment at present and in the future, it is essential to determine which types of materials are sorbing radioactive cesium in Fukushima.

Mukai et al. (2014) investigated radioactive particles

doi:10.2465/jmps. 150722

S. Motai, motai@eps.s.u-tokyo.ac.jp Corresponding Author in the actual contaminated soil near the Fukushima Daiichi nuclear power plant using autoradiography with imaging plates (IPs) as well as electron microscopy. They classified the radioactive particles into three categories mainly on the basis of their morphologies and chemical compositions: weathered biotite (WB) with a plate-like morphology, aggregates of fine minerals (AM), and particles mainly consisting of organic matter (OM). However, structural characterization, which is often performed using diffraction techniques, was not carried out, particularly for the individual particles.

Accordingly, in this study, structural characterization of individual radioactive particles was performed using $\mathrm{X}$-ray diffraction with a micron-sized $\mathrm{X}$-ray beam generated by synchrotron radiation (hereafter abbreviated to SR- $\mu$-XRD). This method was chosen because it is difficult to obtain XRD patterns with a sufficient signal-tonoise ratio using a conventional $\mathrm{X}$-ray source for particles that are several tens of micrometers in size. Additionally, the features of WB in the Fukushima area were investigated for comparison, using conventional XRD and X-ray 
Table 1. The radioactive particles subjected to $\mathrm{SR}-\mu-\mathrm{XRD}$ and their properties

\begin{tabular}{clc}
\hline $\begin{array}{c}\text { Sample } \\
\text { No. }\end{array}$ & \multicolumn{1}{c}{$\begin{array}{c}\text { Elements detected by } \\
\text { SEM-EDS }\end{array}$} & $\begin{array}{c}\text { Radioactivity } \\
(\mathrm{Bq})\end{array}$ \\
\hline WB-1 & $\mathrm{O}, \mathrm{Mg}, \mathrm{Al}, \mathrm{Si}, \mathrm{K}, \mathrm{Ti}, \mathrm{Fe}$ & 0.013 \\
WB-2 & $\mathrm{O}, \mathrm{Mg}, \mathrm{Al}, \mathrm{Si}, \mathrm{K}, \mathrm{Ti}, \mathrm{Fe}$ & 0.008 \\
WB-3 & $\mathrm{O}, \mathrm{Mg}, \mathrm{Al}, \mathrm{Si}, \mathrm{K}, \mathrm{Ti}, \mathrm{Fe}$ & 0.013 \\
WB-4 & $\mathrm{O}, \mathrm{Mg}, \mathrm{Al}, \mathrm{Si}, \mathrm{K}, \mathrm{Ti}, \mathrm{Fe}$ & 0.004 \\
WB-5 & $\mathrm{O}, \mathrm{Mg}, \mathrm{Al}, \mathrm{Si}, \mathrm{K}, \mathrm{Ti}, \mathrm{Fe}$ & 0.003 \\
$\mathrm{AM}-1$ & $\mathrm{O}, \mathrm{Na}, \mathrm{Mg}, \mathrm{Al}, \mathrm{Si}, \mathrm{K}, \mathrm{Ca}, \mathrm{Ti}, \mathrm{Fe}$ & 0.008 \\
$\mathrm{AM}-2$ & $\mathrm{O}, \mathrm{Mg}, \mathrm{Al}, \mathrm{Si}, \mathrm{K}, \mathrm{Ti}, \mathrm{Fe}$ & 0.008 \\
$\mathrm{AM}-3$ & $\mathrm{O}, \mathrm{Mg}, \mathrm{Al}, \mathrm{Si}, \mathrm{K}, \mathrm{Ti}, \mathrm{Fe}$ & 0.010 \\
$\mathrm{AM}-4$ & $\mathrm{O}, \mathrm{Al}, \mathrm{Si}, \mathrm{K}, \mathrm{Fe}$ & 0.009 \\
$\mathrm{OM}-1$ & $\mathrm{C}, \mathrm{O}, \mathrm{Mg}, \mathrm{Al}, \mathrm{Si}, \mathrm{K}, \mathrm{Ca}, \mathrm{Fe}$ & 0.053 \\
$\mathrm{OM}-2$ & $\mathrm{C}, \mathrm{O}, \mathrm{Mg}, \mathrm{Al}, \mathrm{Si}, \mathrm{K}, \mathrm{Ca}, \mathrm{Fe}$ & 0.035 \\
$\mathrm{OM}-3$ & $\mathrm{C}, \mathrm{O}, \mathrm{Mg}, \mathrm{Al}, \mathrm{Si}, \mathrm{K}, \mathrm{Ca}, \mathrm{Fe}$ & 0.052 \\
\hline
\end{tabular}

microanalysis.

\section{MATERIALS AND METHODS}

\section{Materials}

The methods of collection and speciation of radioactive fine particles from contaminated soil have been described by Mukai et al. (2014). Besides the particles collected from soil litter in Iitate village (Mukai et al., 2014), radioactive particles were collected in a similar manner from the soil in Ohkuma town, Fukushima, Japan. The morphological and chemical features of the radioactive particles were characterized using a scanning electron microscope (SEM, Hitachi S-4500) with an energy-dispersive $\mathrm{X}$-ray spectrometer (EDS, Kevex Sigma). The particles from Ohkuma were also classified with respect to their morphology and composition as WB, OM, or AM, according to the criteria outlined by Mukai et al. (2014). The Cs-137 radioactivity of each particle was estimated by IP autoradiography with a calibration curve between the intensity of several radioactive particles measured by gamma-ray spectroscopy. The radioactive particles from which the SR- $\mu$-XRD patterns were acquired and their properties are listed in Table 1.

Non-radioactive WB grains were collected from weathered granite in an outcrop in Kawauchi village, Fukushima, which is about $30 \mathrm{~km}$ southwest of the nuclear power plant. Geologically, the granitic rock in this area is categorized as younger Abukuma granite, which also covers Iitate (Kamei et al., 2003).

\section{Methods}

In order to investigate the structure of the fine radioactive particles, SR- $\mu-\mathrm{XRD}$ was carried out using the Japan
Atomic Energy Agency (JAEA) beam-line (BL22XU) at SPring-8. The radioactive particles were attached near the tops of specimen mounts made of Kapton (MiTeGen MicroMounts) with nail manicure or epoxy resin as adhesive using vacuum tweezers (Micro Support VP-SET2) on a micro-manipulator (Micro Support Quick Pro). $\mathrm{X}$-rays of $15 \mathrm{keV}(\lambda=0.8273 \AA)$ were selected from the synchrotron radiation using a monochromator with double $\mathrm{Si}(111)$ crystals, and the samples were radiated through a cross slit of 40 or $60 \mu \mathrm{m}$ width; a collimator with a diameter of $100 \mu \mathrm{m}$ was used to remove scattering from the cross slit and air. The XRD patterns were collected using the single-crystal X-ray diffraction system described by Watanuki et al. (2007). The soil particles were completely immersed in the collimated X-rays. The sample was rotated 180 degrees around the $\varphi$ axis perpendicular to the beam during an exposure period of 120 to 160 s. Angle dispersive diffraction patterns were recorded on a flat IP $400 \mathrm{~mm}$ square, which was located $300 \mathrm{~mm}$ behind the sample. This configuration covered the scattering angle up to $2 \theta=33^{\circ}(d=1.45 \AA)$ entirely and $2 \theta=43^{\circ}(d=1.13 \AA)$ partially. The pixel size to read the IP was $100 \times 100 \mu \mathrm{m}^{2}$, with a pixel number of $4000 \times$ 4000 for one pattern. The two-dimensional X-ray diffraction pattern acquired with the IP was integrated as a function of $2 \theta$ to obtain a one-dimensional profile similar to a conventional powder XRD pattern.

The non-radioactive biotite grains collected from the weathered granite in Kawauchi were powdered and their structure was characterized with conventional powder XRD (Rigaku RINT-Ultima ${ }^{+}$) with Ni-filtered $\mathrm{CuK \alpha}$ radiation. Elemental mapping in the biotite was performed using an electron probe micro analyzer (EPMA; JEOL JXA-8900L) operated at $20 \mathrm{kV}$ and $60 \mathrm{nA}$. The biotite grains were embedded in an epoxy resin, cut perpendicularly to the basal plane, and polished to obtain the cross-sectional surface for the EPMA analysis.

\section{RESULTS}

\section{$\mu$-XRD patterns of weathered biotite (WB) particles}

The two-dimensional XRD pattern of a radioactive particle classified as WB is shown in Figure 1. The pattern shows roughly single-crystalline features, although most peaks are significantly arched, which is probably due to crystal bending and/or mosaicity. A streak with a few intensity peaks on it is observed across the center, which corresponds to the $00 l$ reciprocal row that is perpendicular to the basal plane of biotite, vermiculite, or kaolinite; ideally, their basal spacings should be $\sim 10,14$, and $7 \AA$, respectively (the bottom images in Fig. 1). Figure 2 rep- 
WB-1
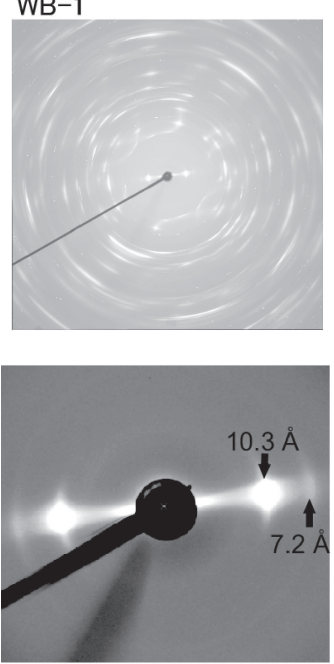

WB-2
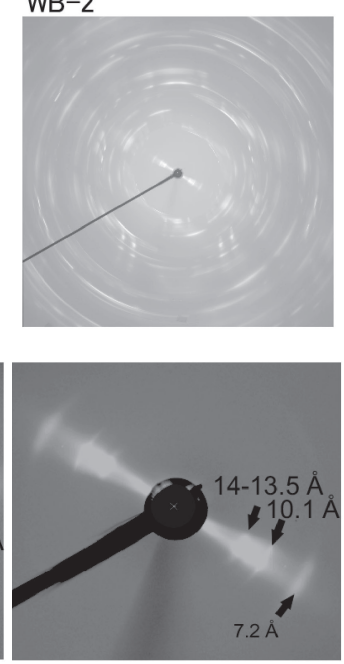

WB-3
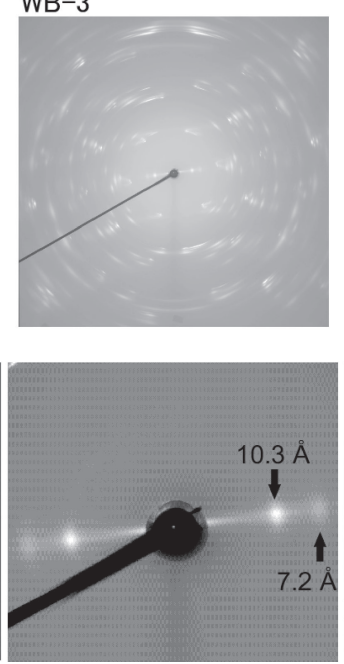

WB-4
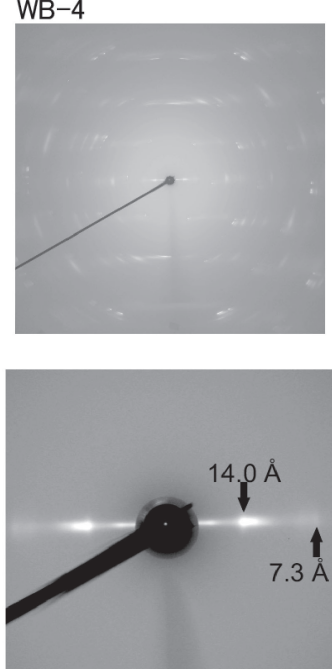

WB-5
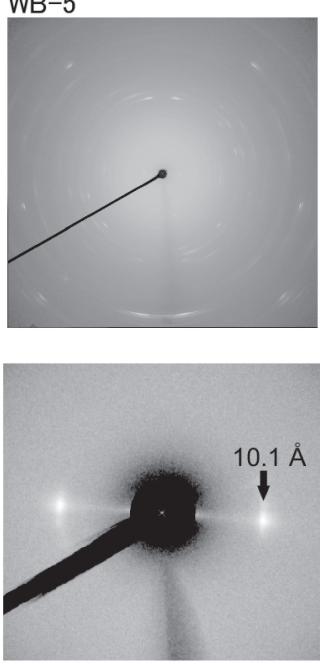

Figure 1. Diffraction patterns for the weathered biotite (WB) particles in Table 1, recorded by rotating the particle during exposure (top). A portion of the pattern near the center (bottom).

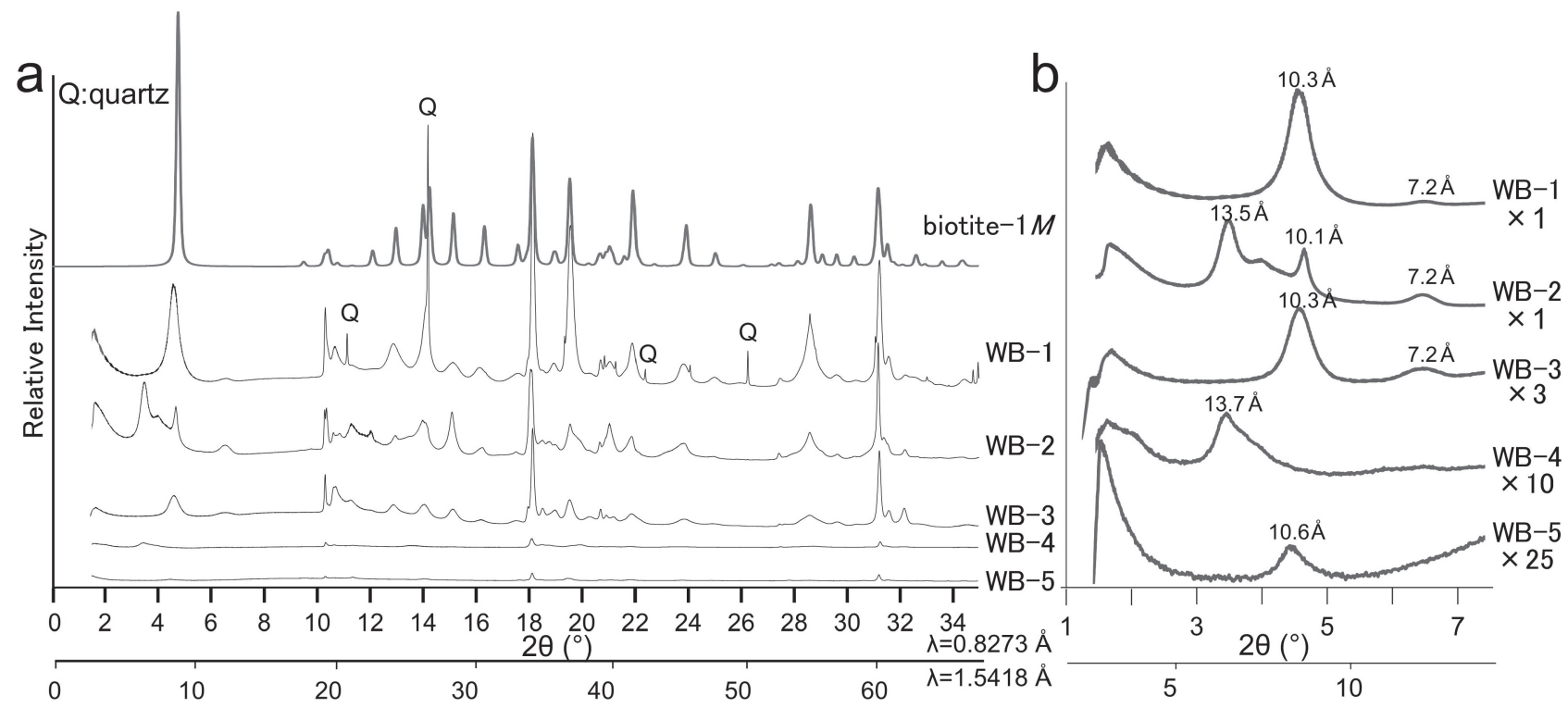

Figure 2. (a) One-dimensional profiles as a function of $2 \theta$ derived from the two-dimensional diffraction patterns on the imaging plate (IP) (Fig. 1) of five weathered biotite (WB) radioactive particles, and the simulated powder pattern for biotite-1M. (b) The low-angle portions of the profiles in (a).

resents the one-dimensional diffraction profiles derived from the two-dimensional diffraction patterns with a calculated powder diffraction pattern for biotite-1 $M$ using the crystallographic parameters reported by Brigatti et al. (1991). For convenience, another scale of $2 \theta$ angles, assuming the wave length of $\mathrm{CuK \alpha}(1.5418 \AA)$ is shown along the horizontal axis. The major peaks of WB-1, 2, and 3, although significantly broadened by stacking disorder, can be roughly explained by biotite- $1 M$ with the exception of the low-angle region at less than $8^{\circ}$, which corresponds to the streak near the center (the bottom images in Fig. 1). For WB-1, 3, and 5, a single peak with $d=10.3-10.6 \AA$ is observed (Fig. 2a), which corresponds to the basal spacing of biotite. However, the $d$-values of the peaks are slightly larger than that for biotite (approximately $d=10.1 \AA$ ) and the peak profiles are significantly broad, indicating that vermiculitization had progressed to some extent in the biotite. On the other hand, WB-2 and 4 show broad peaks with $d=13.5$ and $13.7 \AA$, respectively, indicating that vermiculitization had progressed further. WB-2 also has a relatively sharp peak with $d=$ $10.1 \AA$, indicating the coexistence of a portion of fresh biotite. Beside these peaks, WB1, 2, and 3 show a weak, broad peak with $d=7.2 \AA$, which probably corresponds 

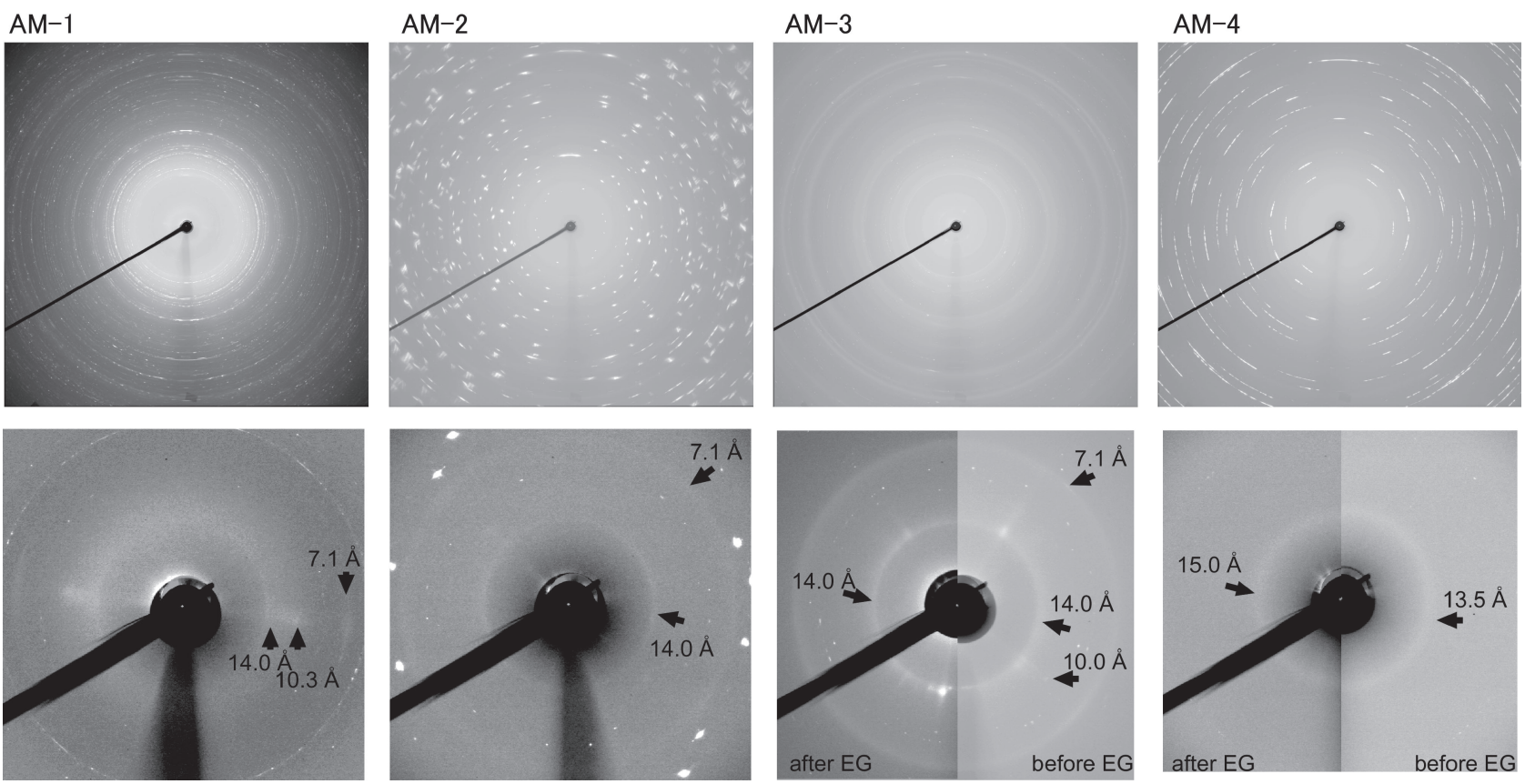

Figure 3. Diffraction patterns of the aggregates of fine minerals (AM) in Table 1 (top). A portion of the pattern near the center (bottom). The patterns for AM-3 and AM-4 combine the patterns before (left) and after (right) ethylene glycol treatment.

to the basal spacing of kaolinite. This peak is also located on the streak near the center and its angular dispersion is similar to that of WB (Fig. 1), which means kaolinite crystals probably exist in WB with their layers parallel to those of biotite, as reported in the TEM analysis of WB by Mukai et al. (2014).

\section{Aggregates of fine minerals (AM) particles}

The two-dimensional diffraction patterns of the AM particles are presented in Figure 3 and the corresponding one-dimensional profiles are shown in Figure 4. Most of the sharp peaks in Figure 4 can be explained by the presence of plagioclase (AM-1), K-feldspar (AM-2), and quartz (AM-4). The diffraction patterns in Figure 3 indicate that the plagioclase in AM-1 and the quartz in AM4 are polycrystalline and form semi-continuous DebyeScherrer rings, whereas the K-feldspar in AM-2 may be monocrystalline. In the low-angle region near the center, a weak streak similar to that observed in WB (Fig. 1) can be observed in AM-1 (Fig. 3), suggesting that a small WB grain exists in the particle. On the other hand, a weak and continuous Debye-Scherrer ring of approximately 14 $\AA$ was identified in AM-2, 3, and 4 (Fig. 3), indicating the existence of fine $2: 1$ type clay minerals with a random orientation in the particles. The patterns of AM-3 and 4 were measured again after impregnation with ethylene glycol (EG). The position of the ring (Fig. 3) and the peak (Fig. 4b) of AM-4 was shifted to a lower angle, which is characteristic of smectite; however, those of AM-3 did not move.

\section{Organic-rich (OM) particles}

The two-dimensional XRD patterns from the three OMs (Fig. 5) contain many fine, sharp spots, indicating the presence of well-crystalline mineral particulates, and an intense halo, probably due to the abundance of various organic substances and/or inorganic amorphous materials. These diffraction spots were mostly identified as quartz and feldspar from the peak positions and intensities in the one-dimensional profile (Fig. 6). Owing to the intense halo or background, Debye-Scherrer rings, which may exist near the center, cannot be observed (the bottom images in Fig. 5). However, the one-dimensional profiles (Fig. 6) contain small peaks at $2 \theta=10.6^{\circ}, 18.2^{\circ}$, and $32.0^{\circ}$ for $\lambda=0.8273 \AA$. The corresponding $d$ values are approximately $4.5 \AA, 2.6 \AA$, and $1.50 \AA$, which are just half of the $b$-length, half of the $a$-length, and the $d$ values for the 060 reflection, respectively, for typical dioctahedral phyllosilicates. In conclusion, the OM particles were confirmed to contain clay minerals as well as fine quartz and/or feldspar fragments. In Figure 6b, a faint peak with $d \sim 14 \AA$ can also be identified, particularly for OM-1.

\section{WB in Fukushima}

SR $-\mu-X R D$ revealed the various stages of vermiculitiza- 

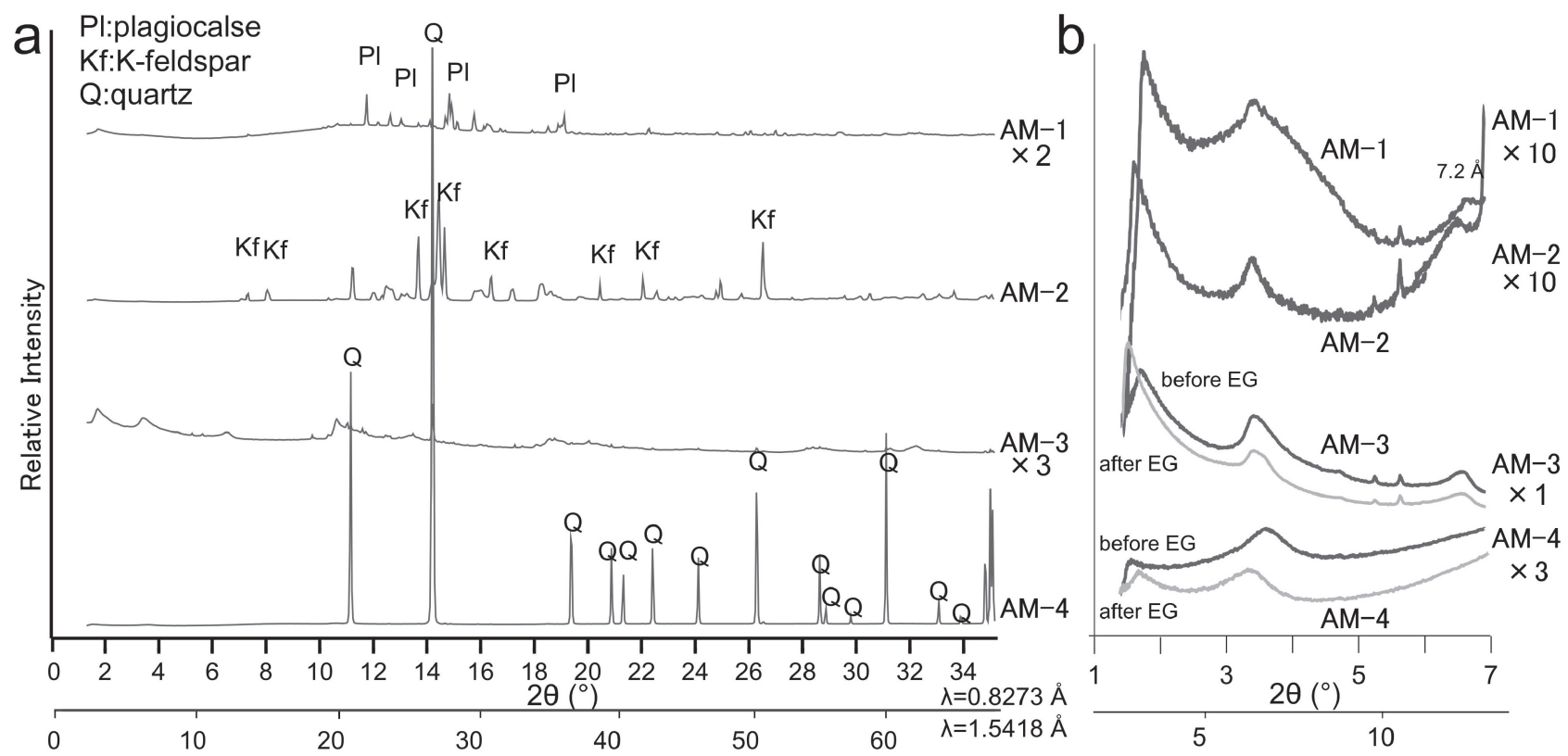

Figure 4. (a) One-dimensional profiles derived from the two-dimensional diffraction patterns on the imaging plate (IP) (Fig. 3) from the four aggregates of fine minerals (AM) radioactive particles. (b) The low-angle portions of the profiles in (a).
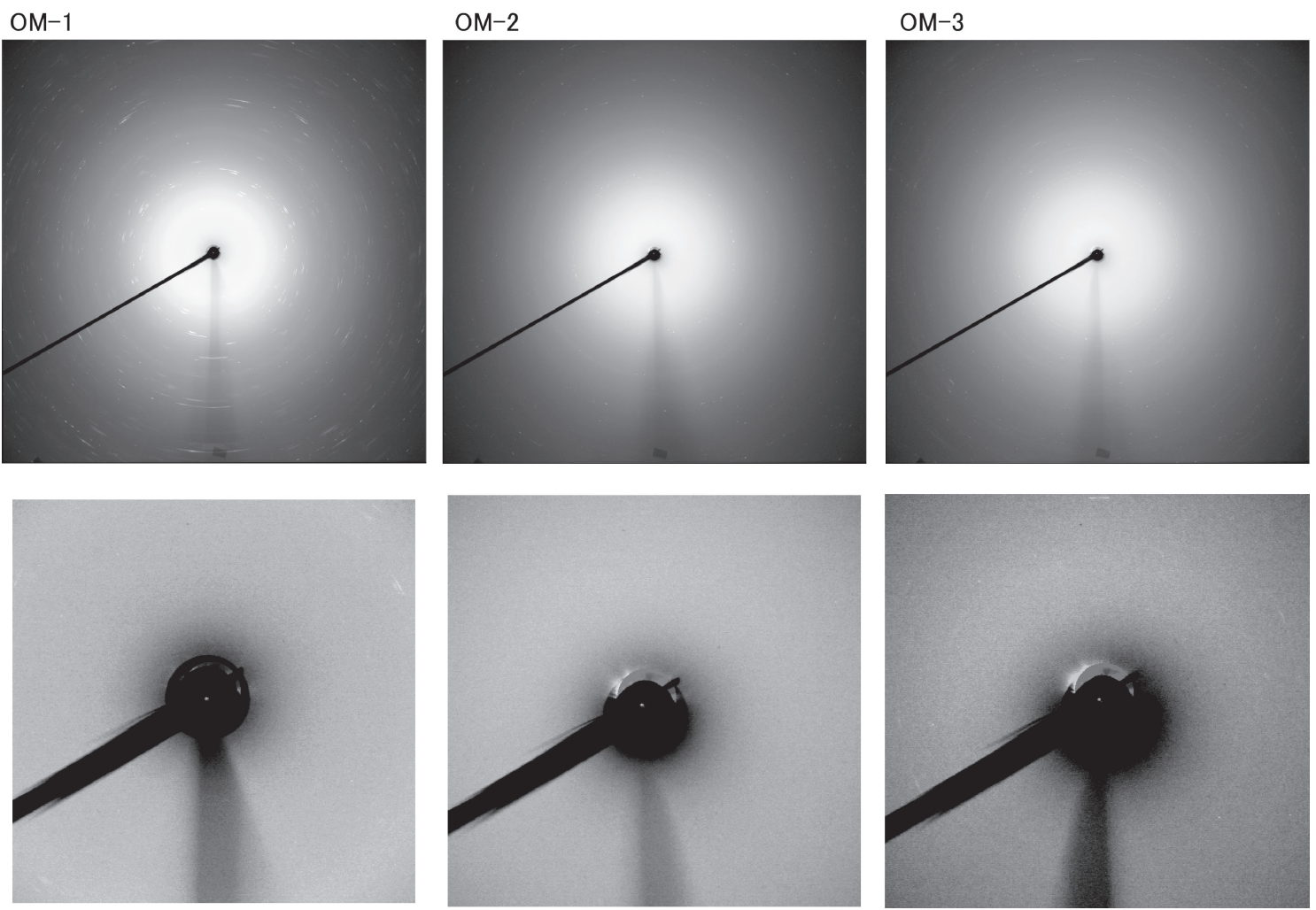

Figure 5. Diffraction patterns from the organic-rich (OM) particles in Table 1 (top) and a portion of the pattern near the center (bottom).

tion for WB and its coexistence with kaolinite. As such, it is of interest whether such variety is observed in Fukushima. Figure 7 shows powder XRD patterns of biotite grains collected from weathered granite in Kawauchi. The pattern of the WB particles contains three broad peaks with $d \sim 14.5,10$, and $7 \AA$ in the low-angle region, probably corresponding to vermiculite-dominant, biotitedominant, and kaolinite regions or grains, respectively. To examine whether these three peaks come from a single biotite grain (the average size of the original biotite grains 

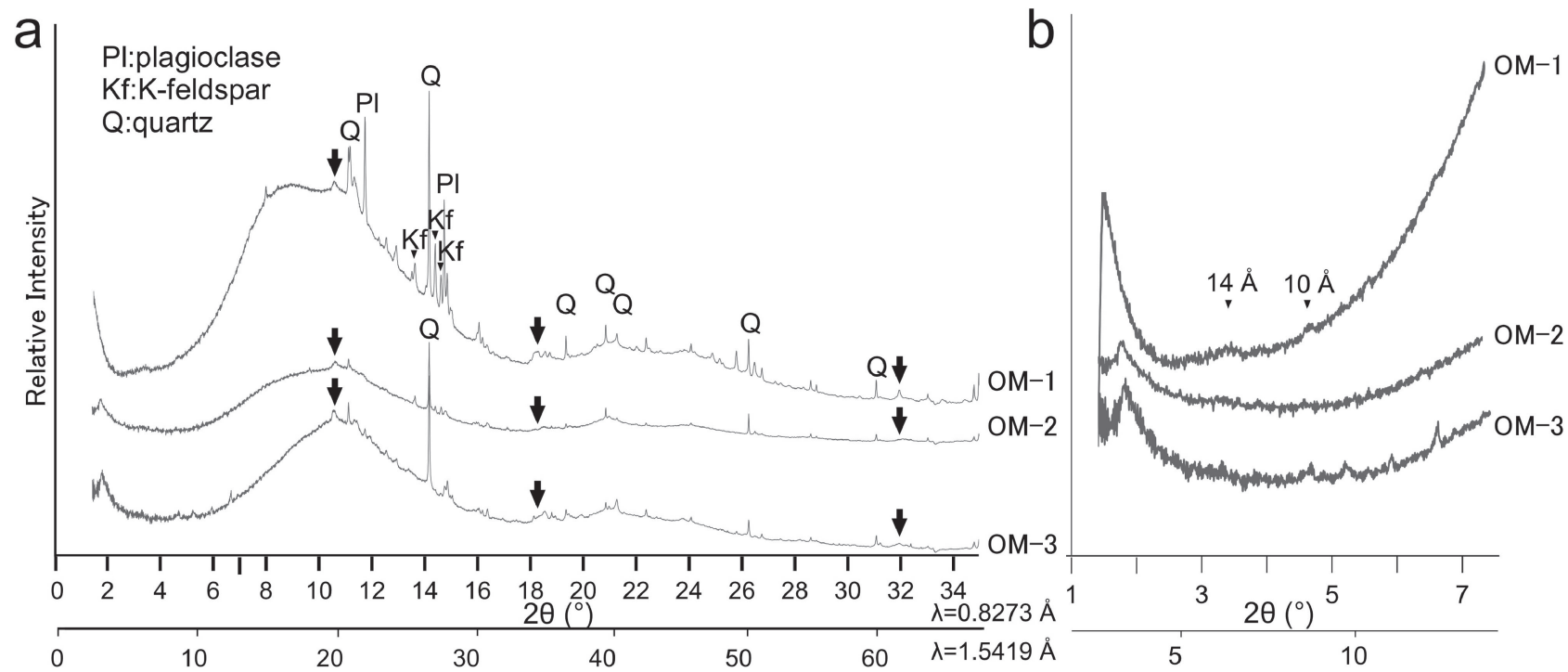

Figure 6. (a) One-dimensional profiles derived from the two-dimensional diffraction patterns on the imaging plate (IP) (Fig. 5) from the three organic-rich $(\mathrm{OM})$ radioactive particles in Table 1. The arrows indicate the peaks that are typical of phyllosilicates. (b) The low-angle portions of the profiles in (a).

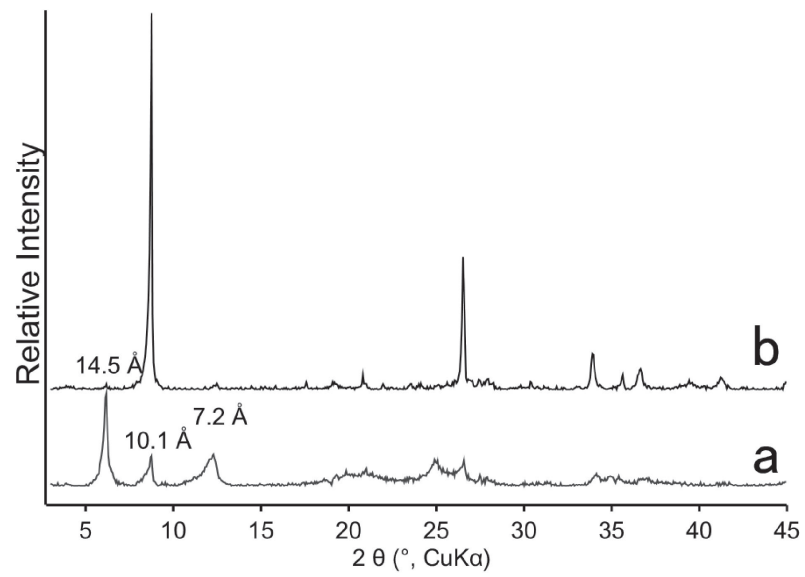

Figure 7. (a) The XRD pattern of powdered and randomly oriented grains of weathered biotite (WB) collected from the exposed weathered granite soil in Kawauchi, Fukushima, about $30 \mathrm{~km}$ southwest of the nuclear power plant. (b) XRD pattern of unweathered biotite collected from the same area for comparison.

in the granite before powdering was around $1 \mathrm{~mm}$ ) or whether they arise separately from different grains, elemental mapping was carried out using the EPMA on the cross-sectional surfaces of the WB (Fig. 8). At first glance, it is clear that potassium $(\mathrm{K})$ is distributed heterogeneously in the grain. This will have occurred as a result of vermiculitization accompanied by the oxidation of iron and leaching of potassium. The heterogeneity indicated that the degree of vermiculitization varies considerably inside a single grain of biotite. The possibility that the potassium-depleted regions correspond to kaolinite is excluded because magnesium and iron are still abundant.
Instead, elongated regions along the cleavages, where aluminum is abundant and other elements $(\mathrm{K}, \mathrm{Mg}$, and $\mathrm{Fe})$ are depleted, were observed, as indicated by the arrows. These regions are probably kaolinite. Considering such an element distribution, it is likely that these WB grains contain the domains to form the reflections of 14,10 , and $7 \AA$ in the X-ray diffraction pattern within a single grain.

\section{DISCUSSION}

\section{Characteristics of WB}

In general, the weathering of mica is routinely evaluated by the peak profile of the basal reflection, which originally had a $d$-value of $\sim 10 \AA$, with a sufficiently narrow peak width. The basal reflection for the radioactive WB particles showed significant broadening and a $d$-value slightly larger than $10.1 \AA$ (WB-1, 3, and 5) or similar broadening with $d \sim 13.5 \AA$ (WB-2 and 4) (Fig. 2b). These various diffraction profiles indicate different degrees of vermiculitization for the radioactive WB particles. WB-2 and 4 are definitely more vermiculitized than WB-1, 3, and 5. However, from comparison of the radioactivity for each WB particle (Table 1) and the XRD results, it does not seem likely that the amount of fixed radioactive cesium and the degree of vermiculitization are correlated. For instance, the location of these particles in the soil, such as the depth from the surface and/or the heterogeneity of the abundance of the WB particles, also influences the amount of sorbed radioactive cesium for each particle. 

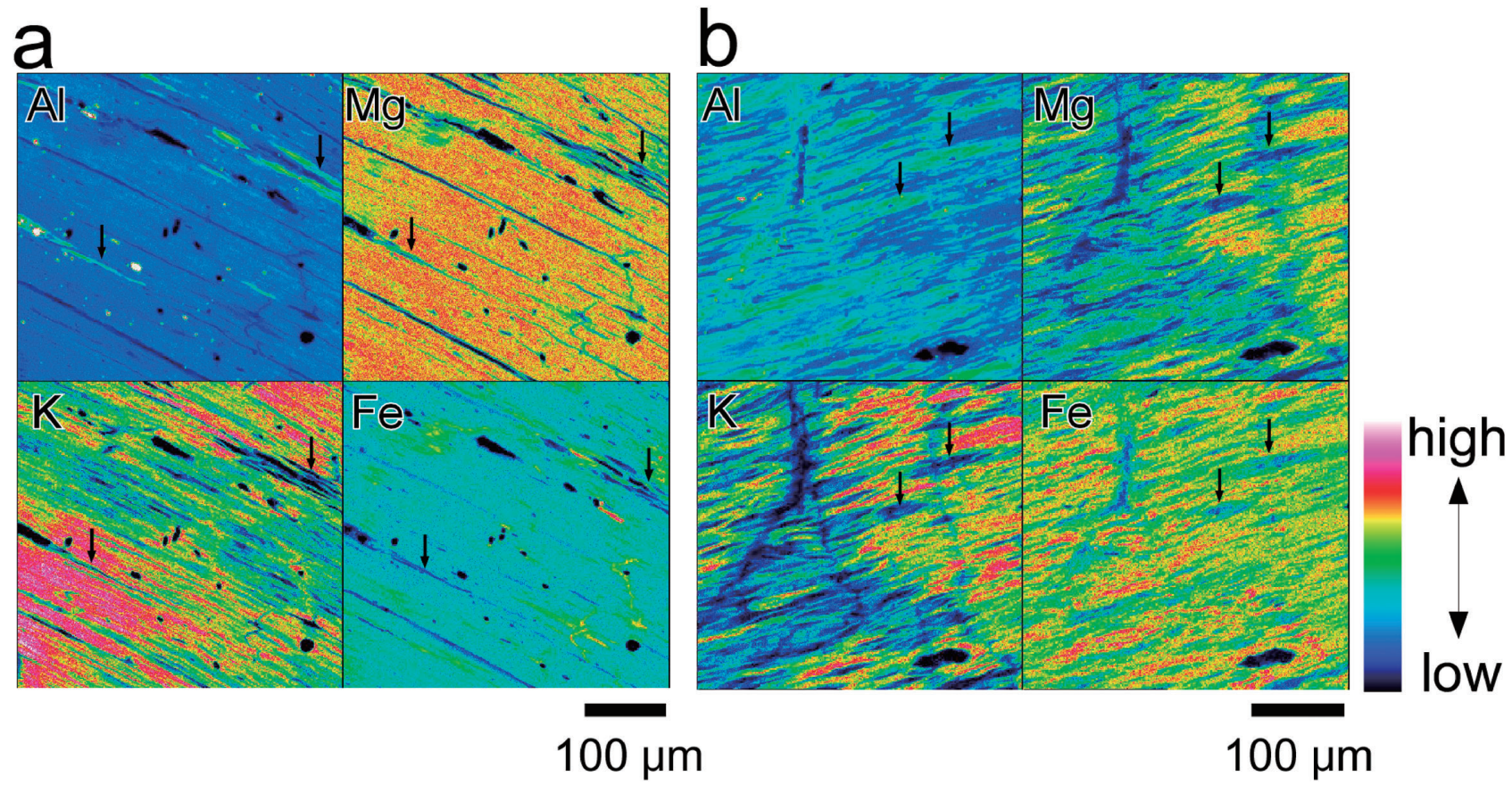

Figure 8. Elemental maps acquired from the cross-sectional surfaces of two weathered biotite grains collected from the weathered granite soil exposed in Kawauchi, Fukushima. The regions indicated by the arrows are rich in $\mathrm{Al}$, depleted in $\mathrm{K}, \mathrm{Fe}$, and $\mathrm{Mg}$, and probably consist of kaolinite.

Although the radioactive WB particles were collected from only two localities, the SR- $\mu$-XRD indicated that their degree of weathering varied significantly. The analyses of the WB grains collected from the outcrop of weathered granite in Kawauchi indicated that a single WB grain of around $1 \mathrm{~mm}$ in size contained heterogeneous domains with various stages of vermiculitization. If such grains are fractured to form particles of several tens of micrometers in the same manner as for the radioactive WB particles investigated in this study, it is postulated that some of them will show $14 \AA$ reflections (intensely vermiculitized), some will show reflections near $10 \AA$ (weakly vermiculitized), and some will show both in the SR- $\mu$-XRD patterns, as shown in Figure 2. Although more investigations on weathered granitic rock in other localities would be necessary to draw general conclusions, it is suggested that the variety in the structure of the radioactive $\mathrm{WB}$ particles found in the $\mathrm{SR}-\mu-\mathrm{XRD}$ analysis is not related to specific areas or to the degree of weathering of the rock in Fukushima, but it can be attributed to the heterogeneity of the vermiculitization of biotite at a single-grain sized scale.

\section{Characteristics of clay minerals in $\mathrm{AM}$ and $\mathrm{OM}$}

In the $\mathrm{SR}-\mu-\mathrm{XRD}$ patterns of the $\mathrm{AM}$ and $\mathrm{OM}$ particles, there are no clear peaks corresponding to WB except in that of AM-1. Most of the AM and OM particles contain detrital rock-forming minerals such as quartz or feldspar. However, it is unlikely that these minerals are cesium adsorbents (e.g., Cornell 1993). The SR- $\mu$-XRD patterns from radioactive particles of $\mathrm{AM}$ and $\mathrm{OM}$ indicated the presence of minute $2: 1$ type clay minerals with broad peaks of ca. $14 \AA$ in all particles. From the peak positions of the reflections around $d \sim 1.5 \AA$ and the chemical analysis, these clay minerals appear to be dioctahedral. The peak shift after EG treatment indicates that AM-4 contains a smectite-like mineral. On the other hand, the peak of AM-3 did not shift. Hence, the mineral may have a higher layer charge similar to that of vermiculite. However, this mineral is completely different from vermiculite topotactically transformed from biotite, which inherits the tetrahedral sheets, because the crystal size is small enough to form continuous Debye-Scherrer rings (Fig. 3). Fujii et al. (2015) reported from the results of a sorption experiment in the laboratory that fine 2:1 type clay minerals other than WB adsorbed cesium efficiently in paddy soil collected from Iitate. The fine clay minerals identified in this study may be identical to those reported. For OM particles, the peaks corresponding to dioctahedral 2:1 type clay minerals are also distinct in Figure 6. These clay minerals are expected to retain radiocesium. However, it cannot be ruled out that the amorphous material in the particles, which may contribute to forming 
the intense halo in the SR- $\mu$-XRD pattern as well as the organic matter, is responsible for the Cs-adsorption.

\section{CONCLUSIONS}

SR- $\mu$-XRD of radioactive WB particles showed various diffraction patterns. Considering the position and broadening of the basal reflection with $d=10-14 \AA$, it is certain that all the WB grains were vermiculitized to a greater or lesser extent. Parallel growth of kaolinite in the WB crystals was also common. Examination of WB collected from weathered granite in Fukushima suggested that the various stages of vermiculitization accompanying kaolinite growth can be attributed to the heterogeneity in a single WB grain in the weathered granite. The SR $-\mu-\mathrm{XRD}$ patterns of radioactive particles categorized as $\mathrm{AM}$ and OM indicated the presence of minute 2:1 type clay minerals in all particles. From the peak positions and chemical analysis, this mineral is thought to be dioctahedral.

\section{ACKNOWLEDGMENTS}

We are grateful to $\mathrm{H}$. Yoshida for assisting us with the EPMA analyses. We also thank H. Kaneko for technical support. Part of this work was supported by a Grantin-Aid for science research (No. 2434133 and No. 15H04222) by MEXT, Japan. This work was also supported by the 2014 JAEA contract research for Fukushima environment recovery, 'Study on Cs adsorption and desorption process on clay minerals', and performed partly under Proposals No. 2014A3701 and No. 2014B3701 in BL22XU at SPring-8.

\section{REFERENCES}

Bellenger, J.P. and Staunton, S. (2008) Adsorption and desorption of ${ }^{85} \mathrm{Sr}$ and ${ }^{137} \mathrm{Cs}$ on reference minerals, with and without inorganic and organic surface coatings. Journal of Environmental Radioactivity, 99, 831-840.
Brigatti, M.F., Galli, E. and Pppi, L. (1991) Effect of Ti substitution in biotite-1M crystal chemistry. American Mineralogist, 79, 1174-1183.

Cornell, R.M. (1993) Adsorption of cesium on minerals: A review. Journal of Radioanalytical and Nuclear Chemistry, 171, 483500 .

Dumat, C. and Staunton, S. (1999) Reduced adsorption of caesium on clay minerals caused by various humic substances. Journal of Environmental Radioactivity, 46, 187-200.

Fujii, E., Tamura, K., Hatta, T., Yamada, H., Yaita, T. and Kogure, T. (2015) Cesium sorption to paddy soil in Fukushima. Clay Science, 19-2, 7-22.

Giannakopoulou, F., Haidouti, C., Chronopoulou, A. and Gasparatos, D. (2007) Sorption behavior of cesium on various soils under different $\mathrm{pH}$ levels. Journal of Hazardous Materials, $149,553-556$.

Kamei, A., Takagi, T. and Kubo, K. (2003) Geology and petrography of the Abukuma granites in the Hiyama district, Fukushima Prefecture, NE Japan. Bulletin of the Geological Survey of Japan, 54, 395-409.

Kim, Y. and Kirkpatrick, R.J. (1997) ${ }^{23} \mathrm{Na}$ and ${ }^{133} \mathrm{Cs}$ NMR study of cation adsorption on mineral surfaces: Local environments, dynamics, and effects of mixed cations. Geochimca et Cosmochimica Acta, 61, 5199-5208.

Mukai, H., Hatta, T., Kitazawa, H., Yamada, H., Yaita, T. and Kogure, T. (2014) Speciation of Radioactive Soil Particles in the Fukushima Contaminated Area by IP Autoradiography and Microanalyses. Environmental Science and Technology, 48, 13053-13059.

Takahashi, Y., Makide, Y., Minai, Y., Ambe, S. and Ambe, F. (1999) Comparison of adsorption behavior of multiple inorganic ions on kaolinite and silica in the presence of humic acid using the multitracer technique. Geochimca et Cosmochimca Acta, 63, 815-836.

Watanuki, T., Machida, A., Ikeda, T., Ohmura, A., Kaneko, H., Aoki, K., Sato, T.J. and Tsai, A.P. (2007) Development of a single-crystal X-ray diffraction system for hydrostatic-pressure and low-temperature structural measurement and its application to the phase study of quasicrystals. Philosphical Magazine, 87, 2905-2911.

Manuscript received July 22, 2015

Manuscript accepted March 7, 2016

Published online June 8, 2016

Manuscript handled by Tsutomu Sato 